\title{
JOSÉ GARCÍA, MAESTRO MAYOR DEL CONCEJO HISPALENSE
}

\author{
POR FERNANDO CRUZ ISIDORO
}

\begin{abstract}
Este artículo trata de reflejar la biografía y la actividad laboral del arquitecto José García, que trabajó en la Sevilla de fines del siglo XVII y principios del XVIII, recogiendo su catálogo de intervenciones. Con ello pretendemos revalorizar su figura e ir desvelando aquellas personalidades que hasta ahora se consideraban menores por su desconocimiento.
\end{abstract}

This article tries to reflect the biography and the labor of the architect José García, who worked in the Seville of the ends of the 17th century and beginnings of the 18th century, attending to his catalogue of operations. With it we aim to revalue his figure and to bring to light those personalities that, till now were seen as minor only because they were unknown.

Al igual que ocurriera con sus coetáneos José Tirado o Leonardo de Figueroa, la actividad arquitectónica de José García se desarrolló en las últimas décadas del siglo XVII y en los primeros años del XVIII, gozando de una relativa importancia en el panorama constructivo sevillano, consecuencia de su actividad como Maestro Mayor de Fábricas del Arzobispado y del Concejo Hispalense, que dio como resultado, aparte de sus intervenciones para ambos organismos, una amplia clientela, en parte muy selecta, perteneciente a la nobleza sevillana y a las jerarquías eclesiásticas, con las que entró en contacto en función de dichos cargos, que confiaron en su pericia para la ejecución de importantes obras y reformas en las casas de su morada y en aquellos edificios religiosos en los que ostentaban patronazgo. 


\section{NOTICIAS BIOGRAFICAS Y PROFESIONALES}

Hijo legítimo de Cristóbal García y de Felipa de Santiago, nació en la villa onubense de San Juan del Puerto, en el condado de Niebla, de la que asimismo eran naturales sus padres, siendo bautizado en su iglesia parroquial el 16 de abril de 1642 por el cura don Rodrigo Pérez Conde ${ }^{1}$. Allí debió pasar su infancia y quizás iniciar su aprendizaje como albañil, aunque probablemente un temprano traslado a Sevilla determinó que fuese en esta ciudad donde se produjese su formación y, por supuesto, donde obtuviese el grado de maestro en esta profesión constructiva, dada la inflexibilidad que este gremio sevillano imponía a todo aquel que quisiera ejercerlo en su territorio sin haber obtenido previamente de él dicha cualificación mediante examen. Lo cierto es que, a principios de 1666, contrajo matrimonio en esta ciudad, por lo que para esas fechas debía tener resuelta su actividad profesional y encauzada mínimamente su economía como para decidirse a formar una familia, lo que parece confirmar el hecho de que varios meses antes, el 23 de septiembre de 1665, saliese como fiador de su amigo Esteban García, futuro maestro mayor de la Catedral, en unas obras que éste contrató con el municipio en el matadero de la ciudad, lo que implica tenía ya el grado de maestro y una cierta solvencia económica ${ }^{2}$.

Casó en primeras nupcias el día de San Matías (23 de febrero) de 1666 con María González y León, hija de Bartolomé González y Ana de Medina, vecinos de Sevilla, la cual aportó al matrimonio 400 ducados, dotándola su esposo con otros 200, como constó por escritura ante Bernardo García. Tuvieron cinco hijos: Clemencia María de la Rosa, primogénita, Vicente, Juan, Margarita Josefa y Ana, que murió siendo niña de pecho a los dos meses del fallecimiento de su madre acaecido hacia marzo de 1684 (quizás por complicaciones en el parto), tras una feliz vida conjunta de dieciocho años.

Parece que el deseo de buscar nueva madre a sus hijos menores, amén de otras posibles consideraciones más prosaicas, le decidieran de forma rápida a contraer nuevo matrimonio el día de San Juan Bautista de ese mismo año (24 de junio), apenas transcurridos tres meses del óbito de su esposa y sólo uno del de su hija, lo que por otra parte era práctica frecuente en la época, en que se veía con malos ojos que un hombre adulto, sin votos religiosos, viviese sin casar. La

1. Testamento de José García. HERRERA GARCÍA, Francisco J.: "Noticias de arquitectura (1700-1720)". en "Fuentes para la H.. del Arte andaluz", tomo II. Sevilla, 1990, pág. 77. HERRERA, Fco. y QUILES, Fernando: "Nuevos datos sobre la vida y la óbra de Leonardo de Figueroa", en revista "Archivo Español de Arte", n.o 259-260. Madrid, 1992, pág. 336. El 4-V-1703 declaró tener más de 60 años. FALCON MARQUEZ, Teodoro: "El Palacio de San Telmo". Sevilla, 1900, pág. 61.

2. Archivo Municipal de Sevilla (en adelante A.M.S.), secc. II Contaduría, carpeta 28 n.․ 58. 
elegida fue la doncella María Moreno de la $\mathrm{O}$, que suponemos bastante más joven, hija de Antonio Moreno y de Feliciana Pérez de León, naturales de la villa malagueña de Antequera, la cual llevó por dote 200 ducados de vellón, que García acrecentó en igual cantidad "en arras por razon de su virginidad y limpieza", con la que vivió toda una vida, hasta el final de sus días, casi treinta y dos años, ya que ésta tan sólo le sobrevivió mes y medio. Fruto de su amor fueron ocho hijos, además de otros muertos en edad pupilar: Bernardina, Manuel, María, Isabel de la $\mathrm{O}$, Feliciana María, José, Francisco y Antonio ${ }^{3}$.

A pesar de su crecida prole gozó de una economía bastante saneada, e incluso boyante, algo inusual para el común de los maestros albañiles sevillanos de su tiempo, que sólo llegamos a explicarnos por una enorme laboriosidad impuesta por sus muchas necesidades, que le hicieron no conformarse con las escasas retribuciones monetarias con la que los organismos citados retribuían a sus maestros mayores, e incluso a desistir, como veremos más adelante, de su cargo como arquitecto municipal cuando tuvo que desempeñarlo sin sueldo, ya que el mantenimiento de su gran familia compuesta por trece hijos vivos y la esposa de turno, todos dependientes de él ya que ninguno le llegó a ayudar con su trabajo (hijas a las que casar o hacer monjas e hijos que adoptaron la vida religiosa), le llevó a ampliar al máximo sus actividades laborales, aprovechando la magnífica posición que ambos cargos le supusieron para entrar en contacto con una pudiente clientela, para la que realizó numerosísimos encargos.

Buen ejemplo de ello fueron las diversas casas y el ajuar mobiliario que poseyó, las grandes cantidades que tuvo que gastar para educar y poner "en estado" a sus muchos hijos (más de 163.000 rs.), que mermaron drásticamente su caudal, las fuertes sumas que se le adeudaban en agosto de 1708 (15.960 rs.) y diciembre de 1714 (103.446 rs.) de obras realizadas, incluso con antigüedad, o los importantes restos de su hacienda que aún conservaba en el momento de testar. Cuando hizo declaración jurada el 15 de agosto de 1708 de los bienes que poseía a la hora de la muerte de su primera esposa, en marzo de 1684, declara como, aparte de la vivienda de morada, tenía un solar que había empezado a labrar en las callejas de San Francisco de Paula, propiedad de la parroquia de San Lorenzo, en lo que llevaba gastado unos 3.000 rs. (la arrendó por un año el 15 de julio de 1715 a Rafael Pérez de Luna por 60 rs. mensuales), y además una pequeña "tienda de refino", con seguridad en la propia casa de vivienda, negocio que sería atendido por su esposa, y donde vendían azúcar, cacao, y otros productos al menor, que traían a crédito y pagaban cada semana los sábados, lo que contribuiría de forma eficaz a la economía familiar. El ajuar de la casa, modesto,

3. HERRERA GARCÍA, Francisco J.: "Noticias de arquitectura...", ob. cit.., págs. 72-73, 77-80. 
se componía de 10 sillones de baqueta de moscovia, 3 arcas y un cofre, una cama de barandillas de caoba con su colgadura, diversos colchones, 6 lienzos de a dos varas con la vida de la Virgen, 12 cuadritos pequeños "de los doce de la fama", otro con moldura dorada antigua de la Adoración de los Reyes, 6 laminitas de diferente tamaño, la ropa blanca de vestir de doña María y la abundante de cama y mesa, algunas alhajas ( 3 sortijas, 2 cintillos, 2 pares de sarcillos de oro, una tembladera grande y otra pequeña, 10 cucharas de plata), 13 platos de peltre, "todo genero de loza", diversos cacharros de cocina, un "escaparate grande y gavetones" para la tienda, es decir, una especie de alhacena o armario con puertas y anaqueles, "las herramientas y libros de mi ejercicio", etc., todo lo cual valoraba en $22.280 \mathrm{rs}$, aparte de lo que se le adeudaba (15.960 rs.) ${ }^{4}$.

A la hora de testar, poseía dos casas de morada en el barrio de San Lorenzo, collación en donde está documentada su estancia desde al menos abril de 1708, una, propiedad de dicha parroquia, que todavía no había acabado de labrar y en la que vivían, por la que pagaba 120 rs. de tributo perpetuo, y otra contigua perteneciente al "Santi Espiritu de Triana", en precio de 4 ducados anuales por lo corrido de un tributo perpetuo tomado a la fábrica de San Lorenzo por 5.000 rs. (tras la muerte del matrimonio, una fue arrendada por un año por su yerno Pedro de Falla en 24 rs. mensuales); un solar yermo enfrente de la puerta del Hospital del Amor de Dios, por 30 rs. cada año de tributo a la fábrica de San Martín "el cual no he tenido oportunidad para labrarlo ni servira de provecho a mis herederos, antes si de perjuicio"; y una casa pequeña en la calle Triperas, levantada por "Fulano de la Peña", y que García embargó a su hija y heredera por una deuda de 4.000 rs., y de la que aún no había tomado posesión ${ }^{5}$.

Hombre de sentida religiosidad y de profundo amor a sus numerosos hijos, puso en su cuidado y educación todos sus empeños, tratando por todos los medios de darles una posición segura y firme que, según los cánones de la sociedad hispana de la época, consistía en casar bien a las hijas con maridos de igual "calidad" o superior si se podía, o hacer que profesasen como religiosas, para lo que se las dotaba generosamente, y de dar a los varones una profesión honrosa y provechosa, consiguiendo García que varios de ellos tomasen hábito religioso, lo que conllevaba enorme prestigio y consideración social, y el que gozasen una buena ocupación, con una preparación intelectual superior y un relajado futuro, alejado de las preocupaciones de subsistencia del momento. En su testamento declara como, a Clemencia María de la Rosa la dotó para entrar, con poco más de 20 años, hacia 1688 , en el convento dominico sevillano de Santa María de Pasión, con 1.000 ducados, gastando en el ajuar y otras cosas

4. Ibídem, págs. 72-73.

5. Ibídem, págs. 79-81. 
para su entrada más de otros 1.000 , labrarle aparte celda para su habitación, y de ocuparse de sus gastos durante 28 años; en Vicente, en darle estudios y en los gastos de tomar el hábito en los carmelitas calzados, de ropa "hasta que dejo de leer artes", alimentación, viajes, actos solemnes como su misa cantada, y de una enfermedad que tuvo, empleó 1.000 ducados, aparte de igual cantidad en diversas obras en la casa- grande de dicha orden; a Margarita, casada con el albañil Andrés Cabezas hacia 1701, 1.000 ducados de dote, viéndose obligado en diversas ocasiones a socorrerlos con más de otros 1.200 , además de sacar a su yerno del atolladero de ser prendido por incumplir una obligación de gastar 5.500 rs. en el reparo de un solar que había tomado en la Alameda; del que incluso vendió sus materiales, haciéndose cargo de los pagos que se estaban debiendo y de invertir en su aderezo la citada cantidad, que al final perdió porque no la pudo poner de uso, enajenándola finalmente sin provecho; a Juan, en enseñarle a tocar el órgano antes de entrar en el Carmen Calzado como lego, y en la toma de hábito, 3.600 rs.; a Bernardina, desposada con el albañil José Teodoro hacia 1703, 1.000 ducados, más otros 400 en socorrerla; a Manuela, casada con el carpintero José de Quiroga por esas mismas fechas, igual cantidad; a Isabel de la O, desposada en primeras nupcias, con posterioridad al 30 de abril de 1708, con José Martínez, natural de la villa de Arándiga (Zaragoza), médico graduado, "y por parecerme que iba bien acomodado, me esforce y le di en dote hasta dieciseis mil quinientos reales", en que se incluía alimentarlos y albergarlos en su casa por cuatro años (a razón de 200 ducados anuales o si se marchaban a darles por ese tiempo 6 rs. diarios), entregarle 300 rs. cuando "este apto para el grado de Universalidad" en la facultad de medicina, y 1.500 para el de la reválida (coste del viaje a la Corte y título), además de un completo ajuar (ropa de vestir de su hija, de cama y mesa, dos vestidos completos para cada uno, diversos muebles, joyas, láminas y esculturas, etc.), produciéndose la muerte de su yerno antes de "revalidarse", dejando huérfana una niña de cinco años, Isabel Martínez, de la que García se hizo cargo al igual que de su madre hasta que ésta volvió a casar con Pedro de Falla; a Feliciana, que contrajo matrimonio hacia 1713 con el también médico graduado Francisco Fernández del Castillo, otros 16.500 rs.; a José, cuando ingresó en el convento de los Terceros, en tomar hábito, ajuar, vestuario, y en los cinco años que le mantuvo ayo, hasta 1.000 ducados; y finalmente, a Francisco, que estaba presto para entrar igualmente en dicho convento, para el que también mantuvo ayo por igual tiempo "para que con este cuidado y asistencia aprovechase los estudios", considerando este gasto y el que tendría al profesar, otros $1.000^{6}$.

Aspecto a destacar, y que ya ha sido señalado, fue el de su marcada religiosidad, manifestada como era frecuente en la época de forma ostentosa por una

6. Ibídem, págs. 70-72, 77-80. 
particular devoción a las Animas del Purgatorio y al Santísimo Sacramento, que tuvieron una gran difusión en la Sevilla del momento (surgidas como respuesta de una Iglesia Triunfante tras el Concilio de Trento a las herejías protestantes que las negaban), perteneciendo, como una forma de integrarse socialmente, a la hermandad sacramental de su parroquia de San Lorenzo (a la que dejó en su testamento junto a la de Animas una pequeña limosna). Este espíritu religioso y de austeridad que se vivía en la casa, donde había esparcidos por sus paredes múltiples lienzos y láminas sacras, que sepamos, al menos 6 lienzos con la vida de la Virgen, una Epifanía, y otras estampas de diferentes géneros, y 3 esculturas (Niño Jesús, Inmaculada, y San José, que luego cedió a su hija Isabel), determinaron que seis de sus hijos, animados por la educación que recibieron, decidiesen tomar hábito religioso. Su última voluntad también es elocuente, ya que pide que, en cuanto "en mi vieren señales de muerte", se le llevase el hábito franciscano de la Orden Tercera para amortajarlo, pidiendo ser enterrado en la bóveda de su hermandad sacramental, acompañado por los hermanos de las cofradías del Santísimo, Anima y de Ntra. Sra. de Rocamador, exigiendo, a pesar del espíritu de humildad que parece desprenderse de dicha mortaja, un entierro de primera, ordenando que junto a los acompañantes citados se convidase a otros doce con su limosna, se dijese ese día o al siguiente misa cantada y vigilia de difuntos, y posteriormente otras cien misas rezadas, la cuarta parte en su parroquia ? Sería interesante calibrar hasta qué punto esta "religiosidad" externa era favorable y contribuía a la hora de obtener un cargo importante, como fueron para José García las plazas de maestro de fábricas del Arzobispado, en continuo contacto con los curas y mayordomos de las iglesias que debía visitar y con el provisor a quien tenía que dar cuentas, y en menor medida para la de arquitecto municipal.

En el capítulo de amistades y círculos en los que se relacionó, hay que citar primordialmente la de aquellos maestros y arquitectos con quienes trabajó en diferentes ocasiones, como Esteban García, Francisco Moreno (el 10 de abril de 1715 declaró bajo juramento en el expediente de limpieza de sangre del nieto de éste, Francisco Javier Moreno, señalando como conocía a sus padres y abuelos, a quien había tratado desde hacía 50 años, hasta su muerte, todos cristianos viejos), su cuñado Leonardo de Figueroa (casado en primeras nupcias con su hermana Isabel Quintero) ${ }^{8}$, José Tirado, Diego Antonio Díaz, Juan Pérez de Saavedra, Blas Sancho, sus yernos los albañiles Andrés Cabezas y José Teodoro, etc., siendo interesante apuntar la extraña relación que pudo unirle, por lo dispar de intereses, con individuos procedentes del campo de la medicina y farmacopea,

7. Ibídem, pág. 77.

8. Ibídem, pág. 80. HERRERA, Fco. J. y QUILES, Fernando: “Nuevos datos sobre la vida...”, ob. cit., pág. 336 . 
hasta el punto que dos de sus yernos fueron médicos, y uno de sus albaceas, Bartolomé Bravo Gutiérrez, boticario.

En cuanto a las noticias laborales que hemos podido recopilar, ya citamos como la primera referencia obtenida es la del 23 de septiembre de 1665 , que nos hace suponer cómo para esas fechas sería ya un prometedor maestro albañil, y como presumiblemente estaría en activo con un poco de antelación, siendo momento clave para evaluar el grado de importancia de su carrera profesional, con la superación de una primera etapa como simple albañil a la de perito constructor y tracista, la del 25 de agosto de 1681, en que fue requerido como alarife -cargo que presuponía para su gremio y el municipio ser poseedor de unos conocimientos técnicos superiores-, para que junto al maestro mayor de la ciudad Acisclo Burgueño, el todavía maestro de fábricas del Arzobispado Francisco Moreno, y Sebastián Quintero, diese dictamen de si era apropiado el sitio de San Telmo para levantar el Colegio Seminario de la Universidad de Mareantes, lo que aprobaron ${ }^{9}$.

Otro paso fundamental fue su nombramiento como Maestro Mayor de Fábricas del Arzobispado, tras el desempeño en la plaza de Francisco Moreno, y aun cuando no podemos precisar en qué momento se produjo, podemos utilizar como referentes la fecha anteriormente citada, en que todavía lo era Moreno, y la del 19 de mayo de 1689 , en que ya era ejercida por José García, en la que se informó al cabildo de la Catedral de la petición de la villa de Mairena del Alcor de ensanchar la capilla mayor de su iglesia, según proyecto de "Alonso Moreno, y Joseph García, el primero maestro mayor de obras del exmo. sr. Duque de Arcos, y el segundo maestro mayor de fabricas de este Arzobispado" ${ }^{10}$. Tampoco podemos concretar el momento exacto en que dejó de serlo y, aunque todavía lo era el 12 de septiembre de 1698 , en que por orden del visitador general del arzobispado dictaminó la reparación de la iglesia de San Román ${ }^{11}$, desde hacía unos tres años, desde julio de 1695, hemos documentado cómo José Tirado, maestro mayor de la Catedral, era requerido sistemáticamente por dicha institución, como administradora de las rentas decimales, y a instancias del provisor del arzobispado, para la visita y aprecio de las obras que eran necesarias en diferentes iglesias de la Archidiócesis, lo que nos hace pensar cómo el cargo fue compartido en la práctica desde esos momentos por ambos maestros, aunque sólo García ostentase el correspondiente título. De todas formas, creemos como posible fecha límite de

9. SANCHO CORBACHO, Antonio: "Arquitectura Barroca Sevillana del siglo XVIII". Madrid, 1984, pág. 70. FALCÓN MÁRQUEZ, Teodoro: ob. cit., pág. 49.

10. Archivo de la Catedral de Sevilla (en adelante A.C.S.) Diputación General de Negocios (en adelante D.G.N.) $1695-1700$ n. ${ }^{9} 323$ (5) fols. 83 vto., 84,84 vto.

11. HERRERA GARCÍA, Francisco: "Noticias de arquitectura...”, ob. cit. págs. 175-6. 
su actividad para el arzobispado la de su nombramiento definitivo como arquitecto municipal, lo que aconteció en julio de 1700 , siguiendo interinamente en la plaza Tirado hasta que se procedió a nueva elección en el arquitecto Diego Antonio Díaz ${ }^{12}$.

A pesar de todo el honor que conllevaba esta ascendente carrera y a sus buenas relaciones con el estamento religioso, cuando optó por la plaza de Maestro Mayor de la Catedral tras la muerte de Juan Domínguez, cuya solicitud fue leída junto a las del resto de aspirantes en el cabildo del 29 de octubre de 1691, los señores visitadores de casas a quienes se encomendó dos días más tarde el estudio pormenorizado de los candidatos, no se decidieron por su persona ni por la de otro, como era costumbre, por lo cualificado de todos ellos, por lo que decidieron llevar el asunto al cabildo del 9 de noviembre, donde, tras expresar su opinión sobre los mismos, se votó "canónicamente" a cada uno de ellos, obteniendo José Tirado una abrumadora mayoría de 28 votos, frente a los 10 de Antonio Fernández, tan sólo 2 de José García, y los únicos de Blas Sancho, Alonso Cabezas, y Pedro Romero ${ }^{13}$. Veintitrés años más tarde volvería a intentarlo de nuevo tras la muerte de su amigo José Tirado, pero ya García estaba muy envejecido y poco podía ofrecer a la institución. Al igual que había ocurrido anteriormente, tuvo la mala suerte de que se presentara lo más granado de los maestros sevillanos, todos alarifes, leyéndose en el cabildo del 10 de octubre de 1714 su petición y las de Diego Antonio Díaz, Gaspar de Castañeda, José de San Martín, Cristóbal Portillo, Juan Guisado, Juan Jiménez, Silvestre Tirado -hijo de José Tirado-, Alonso Cabezas, Manuel de Silva, y Francisco Escacena, a las que se unieron el 17 las de Ignacio Díaz y Blas Sancho, decidiéndose finalmente por votación de forma inteligente, por el prometedor arquitecto Diego Antonio Díaz ${ }^{14}$.

Sin embargo, con mucho, el más importante escalón en su carrera profesional fue su nombramiento como Maestro Mayor del Concejo Hispalense, que ejerció durante tres lustros. Cuando se produjo la jubilación en la plaza de Acisclo Burgueño, en el cabildo municipal del 10 de diciembre de 1694, que elevó en su lugar a Juan Pérez de Saavedra (que tenía la futura del cargo), sin ningún tipo de salario, ya que éste se reservaba íntegro como jubilación para Burgueño mientras viviese, se decidió, asimismo, nombrar a José García -igualmente sin sueldo- para suplir las ausencias y enfermedades de Juan Pérez, que en aquellos

12. Desde 1705 Diego Antonio Díaz se titula de tal modo. LÁZARO MUÑOZ, María del Prado: "El arquitecto sevillano Diego Antonio Díaz". Sevilla, 1988, págs. 9-10.

13. SANCHO CORBACHO, Antonio: ob. cit., pág. 179. A.C.S. Actas Capitulares (en adelante Ac. Cap.) de 1691-92 n. 81 , fols. 117 vto, 118 vto, 120 vto y 121 .

14. SANCHO CORBACHO, Antonio: ob. cit. pág. 143; A.C.S. Ac. cap. de 1714 n. 93 fols. $203,214,217,220,220$ vto. 
momentos ya estaba enfermo, por la necesidad de que las obras de la ciudad no parasen, dándole además la futura de la plaza "para que luego que llegue el caso de la bacante para el dicho Juan Perez de Saabedra entre en la propiedad uso y exersisio de dicho ofisio de maestro maior Jose Garcia sin necesitar de otro nombramiento" ${ }^{15}$. Poca paciencia tuvo que emplear, ya que Pérez de Saavedra, gravemente enfermo, a quien sustituyó de forma casi sistemática, murió a los pocos meses, a fines de junio de 1695 , tomando la titularidad el 18 de julio. No obstante, y sin que sepamos la causa concreta, este maestro no llegó a cuajar en el oficio, ni tan siquiera integrarse plenamente en los tan sólo diez meses que lo ejerció en esta primera etapa, en los que apenas si tenemos constancia efectuase alguna intervención, desistiendo finalmente de la plaza, lo que le fue aceptado por el cabildo del 17 de mayo de 1696, que nombró en su lugar al maestro carpintero Luis de Vega, quien tenía la futura de la misma desde el 29 de julio anterior ${ }^{16}$. Las razones que le pudieron llevar a tal extremo, a renunciar a un empleo que tanto honor conllevaba se nos oculta en la documentación, pero a buen seguro sería resultado de un cúmulo de circunstancias, tales como el que en todo ese tiempo no cobrase un sólo real, ya que Burgueño seguía vivo, y no había esperanzas de otra cosa; sus muchas obligaciones al frente de las obras del arzobispado, cargo al que quizás le dijeron tenía que renunciar (a pesar de su mucho provecho), por ser el de la ciudad de ocupación plena; el que tuviese descuidadas sus intervenciones como arquitecto independiente; razones personales, como una enfermedad, lo que no es probable, etc. A pesar de todo, siguió conservando gran ascendiente en la institución municipal, y él mismo seguía considerándose maestro mayor aunque fuese en excedencia, lo que determinó que, tras el fallecimiento de Luis de Vega, se le volviese a reintegrar en la plaza por acuerdo capitular del 9 de julio de 1700 "teniendo esperiensia de la abilidad y sufisiensia de vos Joseph Garcia maestro de obras de arquitectura", despachándosele título muy honroso al día siguiente "para que lo useis y exersais en todos los casos y cosas a el pertenecientes y tengais goseis y lleveis todos los salarios gajes y demas emolumentos a el dicho ofisio pertenesientes segun como los an llebado avido e gozado los demas maestros de albañileria arquitectura y carpinteria desta ciudad y de todas las villas y lugares de su tierra y jurisdiccion os ayan y tengan por tal Maestro Mayor de obras para que os guarden y hagan guardar todas las preeminencias a el dicho ofisio" ${ }^{17}$.

Esta vez sí que logró integrarse en su trabajo, ocupándolo satisfactoriamente durante 15 años, hasta su fallecimiento en enero de 1716. Muerto con antelación

15. A.M.S. sec. II Contaduría carpeta 37 (1694) n. .2 .

16. Ibídem, carpeta 37 (1695) n. ${ }^{\circ}$ 40; 99; carpeta 38 (1697) n.. 15 .

17. LÓPEZ MARTÍNEZ, Celestino: "Arquitectos, escultores y pintores vecinos de Sevilla". Sevilla, 1928, págs. 49-50. A.M.S. sec. Il Contaduría, carpeta 39 (1699) n. 240. 
Burgueño, García ya pudo cobrar íntegramente el salario, que fue de tan sólo 250 ducados anuales, es decir, 2.750 rs., o lo que es igual 7 rs. y medio al día, el mismo que se había venido cobrando por norma desde 1635, ya que no consta que con él se hiciese ninguna excepción, que, por supuesto, le era del todo insuficiente para mantener su prolija familia, consumiéndose su mayor parte en la manutención del caballo que las obligaciones de este oficio le requerían (para acudir con celeridad a las inundaciones e incendios). Tampoco tenemos constancia se le concediera en ninguna ocasión ayuda de costa por estar enfermo, morírsele el jumento, o por su esfuerzo en alguna riada, práctica que fue frecuente con el resto de maestros del XVII para incrementar su escasa retribución.

El endeudamiento que arrastraba el ayuntamiento desde el siglo XVII, determinó que la actividad del arquitecto municipal estuviese constreñida en la práctica, dada la imposibilidad económica de llevar a cabo nuevos edificios o magnas obras urbanísticas, dentro de sus amplias competencias que abarcaban la traza y dirección de toda obra costeada por las arcas municipales, a la reparación y reforma de los edificios públicos deteriorados por el uso (Casas Capitulares, Cárceles Real y de la Santa Hermandad, matadero, carnicerías, pescaderías, alhóndiga...), y a obras de infraestructura urbana que asegurasen el buen desarrollo de la vida cotidiana, como era la prevención y tratamiento de las frecuentes avenidas del Guadalquivir, manteniendo siempre limpios y reparados los husillos, y fuertes murallas y puertas; la extinción de incendios; el preservar el suministro de agua mediante el cuidado de los Caños de Carmona y la red de cañerías internas, manteniendo siempre corrientes las diferentes pilas públicas, para lo que contaba con la colaboración de un cañero mayor; la inspección frecuente del caserío urbano, lo que efectuaba por barrios para detectar las casas que amenazaban ruina, haciéndolas apuntalar o derribar; la conservación de la limpieza de calles y solares, evitando se formasen muladares; etc. En estos cometidos contó con la colaboración del maestro albañil Blas Sancho, que desempeñó de forma interina el oficio previo de suplirlo en ausencias y enfermedades a raíz del mal que lo inmovilizó en cama en noviembre de 1706, aunque oficialmente no se le dio, junto a la futura del cargo, hasta el 25 de febrero del año siguiente, tras solicitud propia ${ }^{18}$. A partir de esos momentos trabajó estrechamente al lado del envejecido García, ocupándose parcialmente de las tareas más ingratas, como fueron el reconocimiento, apuntalado y derribo de las casas ruinosas, asistencia a todas horas de día y de noche en momentos de riadas e incendios, visitas a los Caños de Carmona, y a ejecutar determinadas obras en edificios municipales, sobre todo a partir de 1709, etc., hasta ocupar finalmente el cargo tras la defunción de García.

18. A.M.S. Sec. II Contaduría, carpeta 41 (1707), n. ${ }^{9} 12$. 
A pesar de lo previsor de su testamento, rubricado el 18 de septiembre de 1714 , "estando como al presente estoy sano aunque achaques y poca salud, y en mi acuerdo y sano juicio", la muerte no le llegó a José García hasta dieciséis meses más tarde, el 14 de enero de 1716 -con casi 74 años-, ya que fue enterrado el 15 y, como fue su voluntad, en la bóveda de la hermandad del Santísimo por los beneficiados de su parroquia de San Lorenzo, diciéndosele misa de cuerpo presente, con seguridad, con los deseos ya comentados. Días más tarde, el 2 de febrero, su viuda era nombrada tutora de los hijos menores (Francisco y Antonio), otorgando el 22, junto al resto de albaceas (en el testamento se nombró a sus yernos Francisco Martínez, Pedro de Falla y José Quiroga, y al boticario Bartolomé Bravo), carta de pago por cierta cantidad que se le adeudaba a su esposo. Muy pocos días más le sobreviviría, ya que, viéndose gravemente enferma, y sin posibilidad física de testar, otorgó tal facultad a su yerno Pedro de Falla, muriendo a fines de ese mismo mes, siendo sepultada el 1. de marzo en la misma parroquia ${ }^{19}$.

\section{CATALOGO DE INTERVENCIONES MAESTRO MAYOR DE FABRICAS DEL ARZOBISPADO}

\section{Iglesia de Ntra. Sra. de la Asunción, de Mairena del Alcor}

Por orden del provisor del arzobispado, en la primavera de 1689 inspeccionó esta iglesia que respondía al tipo mudéjar sevillano, de fines del siglo XIV o del $\mathrm{XV}$, para determinar qué reparaciones precisaba, tasándolas en 21.000 rs., siendo llamado poco después para que, junto a Alonso Moreno, maestro mayor del duque de Arcos, diese proyecto de ampliación de su capilla mayor ante "su cortedad, la yncomodidad, que padecia el pueblo para oyr misa, y asistir a los divinos oficios", ya que, cuando se construyó, el vecindario era sólo de 100 almas y ahora sobrepasaba las 600 , para lo que dieron trazas, dibujando las correspondientes planta y montea, valorando la reforma en 26.000 rs. El proyecto trataba de alterar mínimamente el espacio original de tres naves y la cabecera (que habría sido ampliada en el siglo XVI, con la formación de un espacio central y dos capillas laterales cubiertas por armaduras perpendiculares a las naves), y consistió en desbaratar y ensanchar la capilla mayor (que estaría cubierta primitivamente por bóveda de crucería o esquifada), "que sin estender mas la yglesia, con la disposición de abrir nuebos arcos, la hazen capaz de que se

19. HERRERA GARCÍA, Francisco: “Noticias de arquitectura...", ob. cit., págs. 69, 77, 80, 81 y 171 . 
acomode la mayor parte del pueblo", presentando hoy día a la altura del crucero, bóveda vaída, a ambos lados los citados alfarjes, y una pequeña cabecera con media naranja.

Ante lo crecido del coste conjunto, 47.000 rs., la villa solicitó a la Catedral -adjuntando a la memoria el parecer y planta de los arquitectos- asignase la cuarta parte de los diezmos, al igual que había hecho con los 21.000 rs. del arreglo, para sacar la mitad de la demasía, lo que cometió esta institución a su diputación de negocios el 14 de mayo de 1689, que informó de todos estos detalles, indicando cómo el duque de Arcos se había ofrecido a ayudar generosamente en la obra, y cómo para sufragar la otra mitad restante (13.000 rs.), se habían comprometido los vecinos más pudientes del lugar, estimando se enviara al maestro mayor de la Catedral Juan Domínguez "para tomar el conocimiento verdadero de este negocio", constando cómo para el día 24 ya se hallaba en poder de esta diputación su parecer, declarando creía serían necesarios hasta 52.000 rs., ante lo cual la Catedral decidió no mover más el asunto y dar tan sólo los 13.000 pedidos ${ }^{20}$. Nueve años más tarde la obra todavía no se había comenzado, amenazando seria ruina, por lo que el nuevo maestro mayor de la Catedral, José Tirado, con anterioridad al 7 de junio de 1698, volvió a visitar la iglesia, aprobando el proyecto de ampliación, aunque señalando como deficiente el haber dilatado tres varas la capilla porque "es mayor la necesidad que la que habia antes de poderse oyr misa desde las dos naves". Se aprobaron nuevamente los 13.000 rs. solicitados, constándonos cómo para el 27 de julio de 1703 la obra todavía no había fenecido, disparándose los costes con el paso de los años, ya que se habían empleado 51.000 rs., y serían necesarios otros $15.000^{21}$.

\section{Iglesia de Sta. María, de Carmona}

Ante la ruina que presentaba su capilla mayor, al empezar a desunirse las piedras de su bóveda y abiertas unas rafas, la Catedral cometió el 5 de julio de 1694 a su diputación de negocios siguiese los trámites oportunos con el provisor del arzobispado para que mandase maestro que la reconociese, y así poder discernir la proporción de los diezmos a entregar. Sabemos cómo para el 23 de

20. A.C.S. Ac. Cap. $1687-88$ n. 84 fol. 55 vto.; D.G.N. de $1695-1700$ n. 0323 (5) fol. 83 vto., 84, 84 vto., 86 vto., 87. TOAJAS ROGER, M." Ángeles: "Diego López de Arenas. Carpintero, Alarife y Tratadista en la Sevilla del siglo XVII". Sevilla, 1989, págs. 118-121.

21. A.C.S. Ac. Cap. de $1697-98$ n. ${ }^{9} 84$ fol. 85 ; D.G.N. de $1695-1700$ n. 323 (5) fol. 87 vto., 88 ; de 1701-1706 n. .324 (6) fols. 10 vto., 11, 31,46 vto., 50 vto., 51,51 vto., 52, 61, 61 vto., 62 , 85 vto.; Ac. Cap. de 1703-4 n. 87 (1703) fols. 65, 65 vto., 116, 116 vto., 142, 143 vto. (1704), 133 vto. MORALES, A.; SANZ, M.J.; SERRERA, J.M.; VALDIVIESO, E.: "Guía artística de Sevilla y su provincia". Sevilla, 1981, págs. 443-444. La iglesia sufrí una amplia restauración y reforma por Diego Antonio Díaz entre 1720-26. LÁZARO MUÑOZ, María del Prado: ob. cit. pág. 26. 
dicho mes se contaba con un informe del alcalde alarife Antonio Fernández, tasando la restauración en 67.000 rs., que fue adjudicada por mil menos en el maestro Alonso Navarrete, quien dio por fiador al propio Fernández, por lo que la Catedral paralizó cautelarmente el remate, mandando a su maestro mayor Tirado para dar más fiable dictamen, quien lo hizo en 110.000 rs., ya que introdujo nuevas obras por su cuenta, demasía que no gustó a la institución, que pidió el 1..$^{\circ}$ de agosto una tercera visita al provisor eclesiástico, orden que se repitió el 22 de agosto del año siguiente. En el contexto de ambas decisiones se produjo la primera visita de José García como maestro mayor de fábricas, cuyas condiciones, fijadas en 59.500 rs., fueron las que se llevaron a cabo, ordenándosele una segunda inspección el 10 de mayo de 1697, al considerar cómo se estaba obrando mal, lo que así afirmó, dando renovadas trazas con una demasía de 8.500 rs.; viéndose obligado finalmente a una tercera visita en 1698 , ante la necesidad de comprobar si eran necesarios otros reparos en las bóvedas de unas capillas, lo que reconoció en 4.000 rs. ${ }^{22}$.

\section{Iglesia de San Román, de Sevilla}

A instancias del mayordomo de su fábrica, que expuso al provisor eclesiástico en 1698 el precario estado en que se hallaba, José García pasó a reconocerla el 12 de septiembre, dictaminando la necesidad de reparar los tejados, desenvolviendo el de la nave principal y el de la lateral del norte, resanando las tablas de la armadura y la guarnición de las cintas, y tejarlas de canal y redoblón, operación que también se debía repetir en el techo de la sacristía, de unos desvanes, y en el de la capilla mayor; solar las capillas; reedificar el cuerpo de campanas de la torre, cuyo chapitel ya había sido demolido; macizar las grietas que presentaba la bóveda de la capilla mayor (calafateándola y enluciéndola), y algunas tapias de los muros exteriores para calzarlos; etc., ajustando la obra en 15.000 rs. Fue llevada a cabo por el albañil Juan Gómez, que la tenía conclusa para 1701, a excepción del campanario por la polémica que se había originado de si sería conveniente hacer toda la torre, como pretendía el provisor eclesiástico, o tan sólo formar el cuerpo de campanas, como querían los interesados en las rentas decimales que veían peligrar sus intereses (amparándose en el parecer de García). Así las cosas, el 10 de julio de 1703, ya como maestro mayor de la ciudad, y en compañía del albañil y alarife Antonio Fernández, y del maestro mayor de la

22. A.C.S., D.G.N. de $1695-1700$ n. ${ }^{2} 323$ (5) fols. 7,7 vto., 8, 56, 56 vto., 57,57 vto., 58,61 , 61 vto., 62,62 vto., 137 vto., 138; de 1689-95 n. ${ }^{\circ} 322$ (4) fols. 148 vto., 149; Ac. Cap. de 1695-96 n. ${ }^{\circ}$ ' 83 fol. 43; de 1697-98 n. .84 fols. 46 vto., 54 vto.; de $1699-1700$ n. ${ }^{8} 85$ fol. $33,52,65,105$ vto., 139 vto., 140,140 vto., 141,141 vto., 142,142 vto. 
Catedral José Tirado, volvió a inspeccionar la torre por orden de esta institución, haciendo calicata para ver si contaba con suficientes cimientos como para soportar el peso de la nueva construcción, declarando que no, ya que estaban formados por dos varas escasas de fondo, ya podridas, por lo que había que tirar por completo la torre y hacerla de nuevo, de lo que ya se encargó Tirado ${ }^{23}$.

\section{ARQUITECTO INDEPENDIENTE}

Es sumamente interesante la memoria que hizo el 11 de septiembre de 1714 de lo que se le adeudaba en aquel momento, por las noticias que recoge de obras realizadas:

\section{De carácter religioso}

- 17.000 rs. por la reedificación de la vivienda y capilla de Ntra. Sra. de la Estrella, en la calle homónima -Guadalquivir-, en el barrio de la Puerta de San Juan de Acre, que inicialmente estuvo bajo la advocación de San Roque y contaba con un hospital perteneciente al gremio de lenceros, que se perdió, y que cambió su advocación por los hechos milagrosos de la Virgen de ese nombre tras la peste de 1649 , formándose hermandad. González de León recoge cómo la capilla se arruinó del todo el año de 1700 , reconstruyéndose inmediatamente por la citada hermandad y por el marqués de Torres, que costeó la obra -ejecutada por García-, comentando cómo "Esta se labró con bastante amplitud y suntuosidad, de una sola nave con su capilla mayor, y delante de la puerta tiene un pequeño patio cuadrado con habitaciones de la casa" ${ }^{24}$.

- 3.000 rs. de más de 4.000 que había gastado por orden del marqués de Paterna "en las casas de las Animas de San Francisco", hermandad que poseía capilla propia en el claustro grande de dicho convento, de la que aún se conserva la capilla, casa de los capellanes y sacristán, patio, sacristía y salones de la hermandad ${ }^{25}$.

23. HERRERA GARCÍA, Francisco J.: "Noticias de arquitectura...", ob. cit. págs. 69-70, 1712, 175-7. A.C.S. Ac. Cap. de 1703-4 n. 97 fol. 65 vto.; D.G.N. de 1701-1706 n. .324 (6) fols. 52 vto., 53,53 vto., 67 vto., 68,68 vto., 138,138 vto.

24. HERRERA GARCÍA, Francisco J.: "Noticias de arquitectura...", ob. cit. pág. 75. GONZÁLEZ DE LEÓN, Félix: "Noticia Histórica, Artística y Curiosa de esta M.N., M.L., M.H. e I. ciudad de Sevilla". Sevilla reed., 1973, págs. 224-5.

25. HERRERA GARCÍA, Francisco J.: "Noticias de arquitectura...", ob. cit. pág. 76. CASTILLO UTRILLA, María José del: "El convento de San Francisco, casa grande de Sevilla". Sevilla, 1988, págs. 85-88. 
- 250 rs. de más de 1.000 en que entró supliendo a un amigo en la obra de la Capilla del Sto. Cristo de Zalamea, a la salida de la calle del Peral, esquina a la Alameda (en todo el ladrillo cortado, 300 toscos para su bóveda, y en toda la arena y madera).

- Más de 2.000 rs. por obras para las monjas del convento de Sta. Ana y 5.000 para las del Socorro ${ }^{26}$.

- Fuera de esta relación, el 25 de octubre de 1715, junto al carpintero Pedro de Luque, contrató la obra de la casa del capellán de la iglesia del convento de Sta. Rosalía ${ }^{27}$.

\section{De carácter doméstico}

- 27.649 rs. por obras en las casas principales de los marqueses de Rianzuela.

- 19.000 rs. por las realizadas en las casas del mayorazgo de su compadre D. Manuel del Prado.

- 14.000 rs. de las que hizo para D. Francisco Quijano Guerra.

- 7 u 8.000 rs. por las efectuadas en el corral de la Rabeta, propiedad del Hospital de las Bubas, por orden de D. Diego Duque de Estrada.

- 1.500 rs. de las efectuadas en dos casas del lcdo. D. Tomás de Porras en la calle de San Eloy.

- 700 rs. por las realizadas en las casas del abogado de la Real Audiencia D. Luis Galindo en la calle de San Eloy.

- 3.346 rs. de resto de más de 5.600 de las efectuadas en las celdas de las señoras Federigui, por orden del arcediano de Carmona D. Luis Federigui.

- 713 rs. de resto de las realizadas en las casas de su comadre Manuela de Céspedes antes de casarse, y después en las cocinas.

- 245 rs. y medio de los reparos en las casas del veinticuatro D. Sebastián Melgarejo, en el barrio de Santa Cruz.

- 200 rs. de resto por las efectuadas en las del pintor Francisco Pérez.

- 397 rs. por las que hizo en casas de D. Pedro de Ambia, paredañas al jardín de Ntra. Sra. de la Estrella.

- 297 rs. de resto de la efectuada en las del jurado D. Luis Dávila.

- La remuneración completa de las muchas obras que hizo en las casas del estado de Valcarrota por orden del veinticuatro D. Pedro de Olarte.

- 600 rs. de resto de las efectuadas en las casas del escribano Marcos de Alarcón, en la plaza de San Francisco.

26. HERRERA GARCÍA, Francisco J.: "Noticias de arquitectura...", ob. cit. pág. 76.

27. SANCHO CORBACHO, Antonio: ob. cit. págs. 160-1. 
- 800 rs. de resto de los reparos de las casas de morada del marqués de Villafranca, en el callejón de los Estudiantes.

- 1.649 rs. de las de la casa de Pedro Merino, pared y media de San Pedro de Alcántara, en la que vivía D. Lorenzo de Acevedo, asistente en Indias.

- Etc. ${ }^{28}$.

\section{Como alarife}

Como citamos en otra parte, en tal calidad fue requerido junto a otros maestros el 25 de agosto de 1681 para que diese su parecer sobre ubicar la Universidad de Mareantes en el sitio de San Telmo, siendo requerido años más tarde por esta institución para informar del estado de su construcción, paralizada desde fines del XVII, lo que efectuó el 4 de mayo de 1703 junto al alarife carpintero Juan de Oviedo ${ }^{29}$.

El 27 de febrero de 1692 acudió a una reunión de expertos formada por Acisclo Burgueño, Pedro Romero, Juan Afanador, Manuel García, y Juan Durán, para determinar si la iglesia de la casa profesa de jesuitas - de la Anunciaciónamenazaba ruina, reconociendo que no ${ }^{30}$.

En septiembre de 1697 superviso las trazas del cantero Lorenzo Fernández de Iglesias para la ejecución de una portada de piedra para la casa que el canónigo Andrés de Ibarburu y Galdana tenía en la calle Castro; siendo solicitado en 1709, junto a José Tirado, Juan Navarro, Diego Antonio Díaz, y José de Escobar, para que alguno de ellos se hiciese cargo de la obra de reparación que este último, maestro mayor del Alcázar, proyectó en la Casa de Contratación, a lo que todos se negaron por ser escaso el presupuesto de $17.243 \mathrm{rs}^{31}$.

Para la concesión a su colaborador Blas Sancho de una casa en el barrio de San Gil a tributo perpetuo, propiedad de la Cartuja de las Cuevas, fechado el 3 de abril de 1712, informó sobre su estado; apreciando el 8 de mayo, junto a Francisco Martín, el solar que inmediato a la iglesia de San Lorenzo, en la calle Teodosio, arrendó del convento de la Merced la cofradía del Gran Poder para perfeccionar su sala de cabildos y almacén de pasos, por 33 rs. al año ${ }^{32}$.

El 13 de mayo de ese año, en compañía de José Tirado y Diego Antonio Díaz, inspeccionó un solar junto al convento del Espíritu Santo, propiedad de la

28. HERRERA GARCÍA, Francisco J.: "Noticias de arquitectura...", ob. cit. págs. 75-6.

29. SANCHO CORBACHO, Antonio: ob. cit. pág. 70; FALCÓN MÁRQUEZ, Teodoro: ob. cit. pág. 49.

30. A.M.S. sec. IV Escribanías de Cabildo tomo 20 n. ${ }^{2} 55$.

31. SANCHO CORBACHO, Heliodoro: "Arquitectura del siglo XVIII". En Documentos para la H. ${ }^{a}$ del Arte, tomo VII, Sevilla, 1934, pág. 22. GIL-BERMEJO GARCÍA, Juana: "La Casa de Contratación de Sevilla". En "Anuario de Estudios Americanos", Vol. XXX, 1973, págs. 730-1.

32. HERRERA GARCÍA, Francisco J.: “Noticias de arquitectura...", ob. cit. págs. 133, 73-4. 
Catedral, y dos casas en la calle Clavellinas y Alfaqueque, del citado convento, que iban a permutar para labrar en el solar casa para niñas huérfanas ${ }^{33}$.

A pedimento del duque de Alcalá y Medinaceli, el 7 de julio por la mañana temprano pasó a medir el "túmulo" o sepulcro de D. Per Afán de Ribera y sus dos esposas, que se encontraba en la capilla mayor del monasterio de Sta. María de las Cuevas -donde se encontraba efectuando obras, al parecer en la iglesia-, porque entorpecía el lugar y se quería trasladar al lado de la epístola, señalándose como medía 2 varas y media en cuadro los tres bultos de mármol y los cuatro escudos de armas, y 7 cuartas de alto.

El 10 de julio de 1714, como maestro mayor de la Ciudad, y junto al carpintero Pedro de Luque y el albañil alarife José García de Marta, declara cómo fue por orden del administrador del Estado de la Algaba para dictaminar qué obras eran necesarias en las casas principales de dicho estado, tasando las de albañilería en 5.500 rs. y las de carpintería en $2.200^{34}$.

\section{MAESTRO MAYOR DEL CONCEJO HISPALENSE}

Previamente reseñar cómo en el breve intervalo de tiempo que ejerció la plaza en su primera etapa, tan sólo le he documentado tres intervenciones:

- La reparación efectuada en los tejados de las Casas Capitulares a fines de 1695, que estaban terminadas para el 16 de enero del siguiente.

- La obra realizada bajo su dirección en el matadero por el albañil Diego de Chaves y el carpintero Juan Durán, entre el 9 de enero y el 17 de abril de 1696, con un coste de 2.490 rs. y medio que certificó el 5 de mayo.

- La certificación del 4 de mayo de que Juan Durán había cumplido con su obligación de reparar las tablas de las carnicerías públicas ${ }^{35}$.

\section{A. En edificios públicos}

\section{Casas Capitulares}

El 31 de agosto de 1702, certificó cómo a lo largo de ese año se habían efectuado diversas reparaciones sobre este edificio, como fue el recorrer los tejados y azoteas, arreglar "las puertas de las rejas" y la escalera que salía a ella, poner argollas de hierro, fijar una puerta con plomo, componer una ventana, etc.,

33. Ibídem, pág. 27. LÁZARO MUÑOZ, M. el Prado: ob. cit. pág. 42.

34. HERRERA GARCÍA, Francisco J.: "Noticias de arquitectura...", ob. cit. pág. 74, 172.

35. A.M.S. sec. II Contaduría carpeta 38 (1696) n. ${ }^{2} 63 ; 62 ; 59$. 
con un coste de 820 rs.; declarando el 14 de abril de 1704, entre otras obras, como al tiempo de empezar a montar los andamios para una fiesta de toros y cañas en la plaza de San Francisco, se hundió un tabique de cerramiento "del oficio que esta dentro de las rejas del cabildo", levantándolo de nuevo con un oficial y peones, de un ladrillo de grueso, en lo que gastó 103 rs.; encargando ese otoño, por orden capitular del 4 de octubre, a su yerno el albañil José Teodoro, reparase los tejados, particularmente el de la contaduría, con canal y redoblón, y el de los cuartos del alcaide, en lo que se trabajó 24 días (empleándose 23 cahíces de cal, 2 cargas de yeso, 80 de arena y 104 de tierra, 4.500 canales, 200 ladrillos y 10 cargas de medios), con un coste de 2.771 rs., lo que certificó García el 7 de noviembre. El 14 de ese mismo mes se ordenó el arreglo de la sala del archivo, colocándole una vidriera, cuyo marco de madera labró el carpintero Juan Durán, causándose un gasto de 462 rs., en que se incluía la red de alambre, vidrios y manufactura; efectuando García, entre el 22 y el 25 de junio de 1705 , la retirada de una higuera de dentro del edificio, el solado de parte de la azotea que cubría la escalera principal, el desenvolver un tejado, y otras cosas menores, en lo que consumió 322 rs. ${ }^{36}$.

\section{Cárcel Real}

Por orden capitular del 28 de junio de 1702, inspeccionó su fábrica para determinar qué reparos eran precisos para asegurar su fortaleza, adoptándose como primera medida colocar "dos golpes por ser necesarios para la seguridad", es decir, dos pestillos o cerraduras fuertes provistos de tal artilugio, que importaron 150 rs., declarando García el 5 de septiembre, cómo el carpintero José de Figueroa y otros oficiales ya tenían terminados y colocados tres postigos fuertes en tres celdas por 621 rs., a los que se añadían otros 73 por un candado grande y tres armellas. Si ya en diciembre de 1709 hubo una importante restauración de las cubiertas del edificio y de su capilla, efectuada por el albañil Francisco de la Reina, que trabajó 18 días, terminándola para el 7 de enero de 1711 con un gasto de 1.354 rs., meses más tarde José García se vio en la necesidad, requerido por el cabildo del 22 de agosto, de volver a inspeccionarla, constándonos cómo para el 17 de noviembre se contaba con su memoria de actuación, que entre otras cosas preveía volver a recorrer los tejados, estimando el costo en sólo 200 rs.

A petición del alcaide de la cárcel, Nicolás de Alabanda, que informó cómo el día anterior, 22 de abril de 1714, se había fugado un preso, realizando diversas roturas en el muro, se le ordenó emitiese parecer de las reparaciones que precisaba, obra que consistió en sacar de cimientos dicha pared, desenvolver el oratorio

36. Ibídem, carpeta 40 (1702) n. 15 (1704) n. 13; 65; carpeta 41 (1705) n. 39 . 
y algunos de los tejados, hacer diferentes divisiones en los calabozos, echar algunas solerías, y en la citada capilla renovar las yeserías y blanquearla, para lo que se desmontó y volvió a colocar el retablo, que se aderezó, tareas que efectuó el alarife Francisco de la Reina entre el 11 de mayo y el 21 de julio, trabajando 58 días con un oficial y varios peones, empleando en madera 40 astas, 60 cuartones, 469 tablas y 4 planchas de castaño, 7.500 ladrillos nuevos y 1.100 raspados para las solerías, otros medios, 8.300 piezas de canal y redoblón, 52 cargas de yeso, cal de Morón, etc., ascendiendo la cuantía a 18.078 rs., 412 de los cuales fueron "por el altar, frontal, lienzo dorar la moldura nueba belo y portes" ${ }^{37}$.

\section{Cárcel de la Santa Hermandad}

Gracias a la petición de su alcaide, José de Posada, atendida capitularmente el 16 de febrero de 1703, recordando cómo a su requerimiento de hacía año y medio José García había emitido informe de su restauración ante lo deteriorada que estaba, y de que la obra todavía no estaba principiada, en la citada fecha se ordenó su ejecución, lo que llevó a efecto el albañil Gregorio Salgado, "a todo lo que asistió el maestro mayor Jose Garcia asi a la disposicion de lo que en dicha obra se a hecho como en el ajuste y concierto de todo genero de materiales", desde el 30 de julio al 22 de septiembre, trabajando 42 días, consistiendo en reedificar el cuarto del alcaide, tanto las paredes como las cubiertas, hacer de nuevo el oratorio, "por lo indecente y asqueroso que estaba", con su cielo raso, puerta, ventana, reja, y solería de ladrillo de junto, recomponiendo el altar, lo que precisó desenvolver los techos de dos aposentos inmediatos, levantando sus paredes y volviéndolos a cubrir; rehacer la cocina alta, por tener podridas las maderas y cayéndose los tabiques, lo que le obligó a realizar diferentes pilares y calzamientos; recomponer las escaleras; hacer siete pares de puertas y reparar el resto; reclavar el zaquizamí de la sala capitular; etc., importando la obra 7.249 rs. y 3 cuartillos, lo que García certificó el 10 de octubre; viéndose obligado días después, por haber entrado nuevo alcaide, a poner nuevas cerraduras y llaves, y a impermeabilizar la sala de visitas por las filtraciones, declarando el 17 de diciembre en 140 los reales empleados.

Por orden capitular del 2 de enero de 1705 volvió a visitar su fábrica, informando el 7 de febrero haber medido 34 tapias de empedrado y realizado un sumidero, en lo que había gastado 881 rs. y medio; efectuando otra inspección con posterioridad al 27 de marzo de 1710, redactando memoria de condiciones por 1.500 rs., entre otras cosas, para retocar el lienzo y puerta de la cárcel, herraje de cerraduras, hacer 8 pares de grillos, resanar las maderas, enjabelgado

37. Ibídem, carpeta 40 (1702) n. ${ }^{9} 62$; carpeta 42 (1711) n..$^{9} 71$; carpeta 43 (1714) n.. 7. 
de muros, etc. Nuevamente, a instancias de su alcaide, fue mandado el 11 de abril de 1714, efectuándose en esta ocasión la limpieza de las oficinas y del sumidero por diez hombres con diez borricos, y la confección por el carpintero Juan Durán por 393 rs. de una poza para recoger las aguas que vertían a la calle. Finalmente, ante el hundimiento de una azotea y lo maltratado de varias puertas, García dirigió a su yerno José Teodoro en su reparación, certificando el 23 de septiembre los materiales y el costo en 389 rs. ${ }^{38}$.

\section{Matadero}

Con su asistencia, con anterioridad al 7 de abril de 1701, el albañil Gregorio Salgado y el carpintero Juan Durán efectuaron diversos arreglos en este edificio, colocando una columna "con su bronce" a la entrada de la puerta principal, y en diversas carnicerías por 3.268 rs.; informando posteriormente cómo se había hundido el lienzo de pared que dividía los corrales del matadero, levantando dicho elemento los dos maestros citados entre el 10 de julio y el 6 de agosto por 1.743 rs.

Del 20 de marzo al 17 de mayo de 1703, dirigió al albañil Jerónimo de Guzmán en la reconstrucción de uno de los muros del edificio (también compró la cal) con un coste final de 11.107 rs.; certificando el 4 de abril una reparación efectuada por Juan Durán, artífice que inició otra a partir del día 23 que, entre otras cosas, colocó una reja por 447 rs. A partir del 23 de octubre García con el albañil Alonso de Prados se ocupó de rebocar las azoteas, calzando las paredes del sitio que servía de cárcel, y de reparar tres ventanas, y en el edificio del Rastro, restaurar su cubierta y rehacer dos tabiques hundidos, todo por 1.591 rs. ${ }^{39}$.

En 1705 se repararon los arcos y todo el peladero del ganado de cerda y un almacén donde se guardaba la leña; ordenándosele visita el 22 de marzo de 1706, obra que corrió ese verano a cargo de Juan Durán por 1.649 rs. y por el carpintero Juan Macías por 389; iniciándose, el 15 de abril de 1709, por su apremio al cabildo del 16 de febrero de que la pared del mirador amenazaba ruina, su reforzamiento, realizándose además diversos calzamientos a los corrales y a los pilares de las crujías, resanado general de todas las puertas y del zaquimazí, etc., por 3.871 rs. A partir del 7 de julio de 1710 se hicieron una pila y otros reparos; con anterioridad al 20 de julio del año siguiente Juan Durán fortificó una puerta de los corrales; entre el 6 de marzo y el 19 de abril este carpintero y el albañil

38. Ibídem, carpeta 40 (1703) n. ${ }^{\circ} 57$; carpeta 41 (1705) n. 69; carpeta $42(1710)$ n..$^{\circ} 50$; carpeta 43 (1714) n.. 7 (1715) n. 36.

39. Ibídem, carpeta 40 (1701) n. ${ }^{\circ} 52 ; 26$ (1702) n. $29 ; 46 ; 63$. 
Juan López por 8.398 rs. realizan otro arreglo y, finalmente, entre el 25 de noviembre y el 7 de diciembre de 1715 , otro por el albañil Juan Guisado ${ }^{40}$.

\section{Carnicerías Públicas}

El 4 de abril de 1703, certificó realizados los arreglos efectuados por su habitual colaborador Juan Durán en diversas carnicerías (en la de la calle Feria introducir un pilar, hacer calzamientos en la pared testera y una puerta, y en la del Altozano e Inquisición, puertas nuevas). En el cabildo del 9 de septiembre de 1711 se entregó memoria rubricada por García de la restauración que precisaba el edificio de la Carnicería Mayor, ubicado en la Alfafa, siendo preciso asegurar los arcos mediante apuntalado, deshacer la capilla, recorrer los tejados, y reparar el rastrillo, obra que realizó, a partir del día 14, el albañil Manuel de Silva (maestro mayor de obras de la Casa de la Moneda) por 2.935 rs., efectuando ese mismo maestro, a partir del 17 de octubre, la demolición de la carnicería de San Vicente para transformarla en una cochera e, igualmente, a partir del 17 de agosto de 1717, el reparo de la Carnicería mayor, haciendo una pared y arreglos en el cuarto del alcaide ${ }^{41}$.

\section{En otros edificios}

Entre el 4 y el 29 de diciembre de 1700 se efectuaron por 2.900 rs. unas obras en los graneros de la Alhóndiga, reparándose las cubiertas, encargándose además García de la compra de parte del material; volviendo a arreglar los tejados, así como la solería y cañería, a fines de 1704; certificando el 5 de octubre del año siguiente cómo, con el albañil Diego de Chaves, había reedificado la casa del Peso de la Harina, y otras accesorias que estaban inhabitables, por 2.347 rs. $^{42}$.

El 6 de julio de 1701 certificó cómo en el palenque de los panaderos donde se vendía este producto en la calle Feria, se necesitaba fortificar las maderas y entablarlo de nuevo, por estar los pies derechos apolillados y las maderas rajadas y desclavadas, estimando el costo en 600 rs., ejecutando la obra Juan Durán por poco más de la mitad de lo presupuestado. Años más tarde, a fines de 1710 , se hizo otra restauración ${ }^{43}$.

40. Ibídem, carpeta 41 (1705) n.9 64 (1706) n.o 41; 55; carpeta 42 (1709) n.o 10 (1710) n.o 41 (1712) n.o 32; 16; carpeta 43 (1714) n.. 7 (1715) n. 26.

41. Ibídem, carpeta 40 (1703) n. .22 ; carpeta 42 (1711) n. 937,$38 ; 34$; carpeta 43 (1714) n. 36 .

42. Ibídem, carpeta $40(1700)$ n. ${ }^{9} 16(1704)$ n. ${ }^{9} 11 ; 46$.

43. Ibídem (1701) n. 28; carpeta 42 (1710) n. 35 . 
Ante la información de que la red o pescadería de la Costanilla se encontraba amenazando ruina, del 3 de septiembre al 13 de noviembre de 1703 dirigió a su yerno José Teodoro, al hermano de éste, y a Juan Durán, en su reconstrucción, empleándose 17.000 ladrillos, 2.500 raspados para la solería, 63 cahíces de cal, 51 cargas de tierra y 9 de arena, 16 palos de castaño y 3 carros de madera, etc., montando 11.820 rs. ${ }^{44}$.

Con antelación al 26 de agosto de 1704, se efectuaron obras en casas pertenecientes al colegio de los Niños de la Doctrina, en la calle de la Amargura, realizadas por el albañil Juan Jiménez y el carpintero Juan de Sierra, que costaron 1.470 rs.; realizando Juan Durán, con la asistencia de García, 13 oficiales y 17 peones, el vallado y enarenado de la plaza de San Francisco para la máscara que se celebró el 30 de ese mes para festejar la victoria de la armada francesa sobre los ingleses en la costa de Gibraltar, en que se gastó 654 rs. ${ }^{45}$.

Ante la petición de la Hermandad Sacramental y de Animas de la parroquial de San Isidoro, de ciertas varas de terreno inservible que eran usadas como basurero, para ampliar su capilla, el cabildo municipal del 8 de agosto de 1704 cometió al procurador mayor y a José García diesen su parecer, que fue favorable, por lo que en la reunión del día 22 se aprobó tal cesión, con la condición de que su maestro mayor estuviese presente a la hora de abrir las zanjas "para que segun su parecer y con su direccion se haga dicha obra", que se inició tras el acuerdo conseguido con el patrono en agosto del año siguiente, demoliéndose la primitiva capilla y construyéndose la que actualmente existe. No está documentado el autor del proyecto, por lo que está dentro de lo posible que García participase en el mismo, aunque se ha señalado la afinidad de su estilo con el de Ambrosio de Figueroa ${ }^{46}$.

El 15 de diciembre de 1707 se comenzó la obra de restauración de la cubierta de la sala donde se guardaba la pólvora en la torre de la Puerta de Triana, la cual se había hundido en parte, temiéndose su ruina por estar las vigas muy apolilladas, enmaderándose un trozo de azotea, gastándose 1.401 rs.; declarando José García, el 21 de noviembre de 1709, cómo había reconocido la cornisa que por la parte de adentro servía como corredor, observando cómo las piedras de la esquina de su vuelo se habían caído los días anteriores, y cómo las inmediatas estaban prestas a hacerlo, con gran riesgo de las gentes, por lo que para evitar una desgracia se debía restaurar de inmediato, lo que efectuó además de otros

44. Ibídem, carpeta 40 (1703) n. 72.

45. Ibídem (1704) n. ${ }^{9} 35 ; 27$.

46. BANDA Y VARGAS, Antonio de la: "Noticias sobre la capilla sacramental de la parroquia sevillana de San Isidoro". En rev. "Archivo Hispalense”. Sevilla, 1982, págs. 199-208. 
reparos en la vivienda, colocándose dos arcos de hierro y tirantes en los balcones, etc., originándose un gasto de 5.380 rs. ${ }^{47}$.

A requerimiento de los curas de la parroquial de San Vicente, el albañil Manuel de Silva entre el 16 y 30 de noviembre de 1711 limpió de escombros un solar que hacía esquina en la calle Redes, cercándolo posteriormente; reparando García, con antelación al 11 de febrero del año siguiente, la casa del Colegio de Niñas Huérfanas, paredaña a la iglesia de la Magdalena, patronada por el ayuntamiento (del que se conserva afortunadamente en el archivo municipal una planta dibujada por su mano, de $31,4 \times 17,5 \mathrm{~cm}$., en tinta ocre sobre papel); certificando el 16 de abril de ese año, cómo se había visto obligado a reedificar casi por completo la casilla de la cal, junto a los Caños en la Puerta de Carmona, que se había hundido, levantando sus paredes, abierto dos ventanas, y colocado reja, gastando 1.197 rs. ${ }^{48}$.

En los meses de abril y mayo de 1715 asistió personalmente al arreglo del molino del Zahorí, en "Charco grande", empleando 2.603 rs., ordenándose el 29 de noviembre la restauración de la casa del husillo de Cantarranas -la que había pertenecido tradicionalmente al maestro mayor de la ciudad-, operación que corrió a cargo del albañil Juan Guisado desde el 16 de diciembre al 15 de enero de 1716 por 2.737 rs. ${ }^{49}$.

Finalmente señalar, como parece intervino inicialmente en la ampliación de la Real Fábrica de Tabacos de San Pedro, que se efectuó desde julio de 1715 hasta finales de mayo de 1716, aumentando su superficie fabril en 1.000 varas cuadradas, para lo que se compraron 6 propiedades, una de las cuales fue apreciada por García como solar (la casa de la calle Morería perteneciente al mayorazgo de $\mathrm{D}$. Pedro de Toledo Golfín) ${ }^{50}$.

\section{B. De infraestructura urbana}

Arreglos de cañerías y fuentes públicas

Contó para estos menesteres con la colaboración del cañero Antonio García ${ }^{51}$. Entre el 12 y el 31 de marzo de 1703, dirigió a los maestros Gregorio

47. A.M.S. sec. II Contaduría carpeta 41 (1707) n. ${ }^{9}$; carpeta 42 (1710) n. 33.

48. Ibídem, carpeta 42 (1711) n. $.^{\circ} 34(1712) n .^{\circ} 50$; 16. (El dibujo en: sec. V Escribanías de cabildo del siglo XVIII tomo $146 \mathrm{n} \cdot{ }^{9} 42$ ).

49. Ibídem sec. II Contaduría carpeta 43 (1715) n.. 38 (1716) n.. 49.

50. OLIVER CARLOS, Alberto: "La arquitectura y el lugar. Análisis histórico urbanístico de una manzana de la ciudad de Sevilla". Sevilla, 1987, págs. 58-60.

51. A.M.S. sec. II Contaduría carpeta 39 (1699) n. ${ }^{2} 32$, carpeta 40 (1701) n..$^{2} 19$ (1703) n. 65 (1704) n. ${ }^{9}$, carpeta $41(1706) n .{ }^{9} 60$. 
Salgado, Diego de Chaves, y Diego de León, y al carpintero Juan Durán que hizo los andamios, en la reparación de los Caños de Carmona, empleando 3.050 rs. y medio, más otros 690 en impermeabilizarlos con zulaque (betún mezcla de cal, aceite y estopa) y en otros reparos; certificando el 8 de enero de 1715, cómo había vuelto a efectuar reparos sobre estos caños, desde San Benito a la Puerta de Carmona, apuntalando su estructura con tablas, para lo que le ayudó su yerno José Teodoro y un carpintero, gastando 224 rs. y medio, y el 11 y 30 de septiembre cómo, por 1.345 rs., había efectuado otros arreglos en diferentes molinos, y por 915 la limpieza de dos lumbreras ${ }^{52}$.

\section{Prevención de avenidas del río}

Dentro de sus obligaciones de mantener limpias todas las alcantarillas de la ciudad para cuando llegasen las lluvias, se incluye su certificación del 14 de enero de 1706 de cómo había gastado en las obras efectuadas en los diferentes husillos por la riada de principios de año, en los que anduvo ocho días de un lado para otro con un caballo alquilado y diferentes operarios, 3.571 rs.; y el 11 de diciembre cómo Mateo de la Cuesta los tenía bien prevenidos para la futura que se avecinaba; habiendo reparado el maestro Manuel de Silva ese otoño las alcantarillas del Pópulo y los pretiles y empedrado de la Calzada de Guadaira ${ }^{53}$.

52. Ibídem, carpeta 40 (1703) n.. 48; carpeta 43 (1715) n.. 36; 38.

53. Ibídem, carpeta 41 (1706) n. ${ }^{\circ} 85$; 11; carpeta 42 (1711) n. $34,36$. 


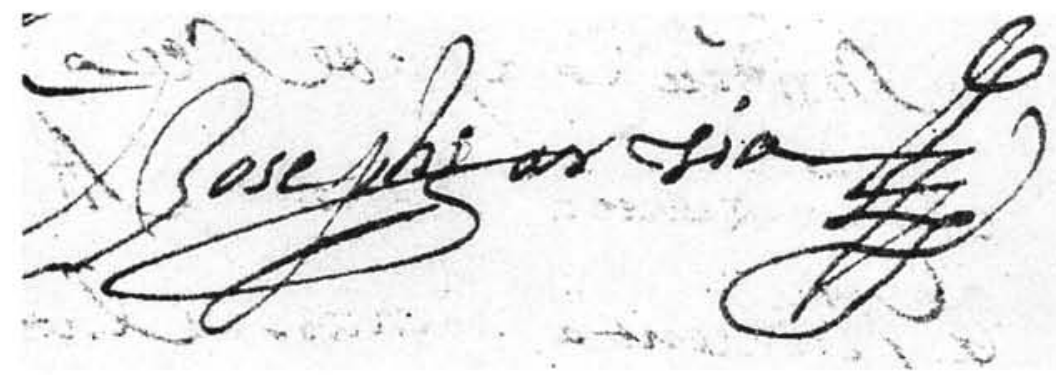

Firma habitual de José García 